\title{
NORTH AMERICA
}

\section{No Hats in Air for Apollo}

\section{from our Astronomy Correspondent}

The Space Science Board of the National Academy of Sciences has come out with yet another quizzical report about the conduct of the United States programme of space research (Lunar ExplorationStrategy for Research 1969-75). This time, the Apollo programme is the centre of the stage, and the board is doubtful not merely of the forward strategy for lunar exploration but also of the wisdom of the detailed planning of the lunar exploration already carried out. Thus it complains of the lack of time for preparing experiments to carry on the early Apollo flights and of the restrictions which have been imposed on the proud possessors of lunar samples, and which may inhibit them from following promising lines of investigation.

Already this year the board has reported on the unmanned exploration of the outer solar system and on the possibilities of an optical telescope in Earth orbit. The telescope report is the most recent (Nature, $224,409 ; 1969)$. The latest report has been produced by a study group which met during the last week in August to decide the best way of using the remaining nine Apollo missions. The study was sadly marred on the first day by the death of the chairman, Professor H. H. Hess of Princeton, who had also been chairman of the Space Science Board since 1962. Professor IV. W. Rubey of California took over as chairman of the study group.

The chief theme of the report is that steps should be taken to exploit as fully as possible the technology of the Apollo project. By implication, there is a lot still to be done. In what is no doubt intended as a reference to the report of the President's task force on the future of manned space flight, the study group says that "we foresee the possibility that a choice will be necessary in the early 1970 s between funding a major new manned exploration technology and the adequate funding of the extensions of Apollo lunar technology". The report says that in such circumstances "the present Apollo lunar exploration phase should be given priority" even if the result is a "significant hiatus in lunar exploration after the Apollo program". Elsewhere, the study group says that it feels "strongly that in the near future the over-all NASA program should not be biased in favour of largescale technological innovations involving manned spaceflight to the detriment of lunar and planetary scientific explorations that fully exploit current technology".

Among other things, the report suggests that the present list of ten landing sites should be supplemented by others chosen in "the most ancient highlands and a youthful mare". The study group also urges that some attention should be paid to increasing the mobility of people on the surface of the Moon in the immediate future by arranging that the Apollo landing modules could remain on the surface of the Moon for up to
72 hours and that people could travel for between 5 and 10 kilometres from the landing point. It asks that there should be instruments in orbits about the Moon to coincide with the lunar landings, particularly in conjunction with the Apollo flights labelled 16 to 20 , by which time it should be possible to develop suitable instruments and even a controlled tracked vehicle for moving about on the lunar surface.

The report gives a great deal of attention to the need for an accurate chronology of the lunar surface. From this it follows that the collection of samples from the surface is a necessary part of exploration. 'The study group emphasizes that the productive planning of this activity will be possible only after the first fow Apollo landings have delineated "the general age range of lunar magmatic and impact history". 'This, no doubt, is why the study group asks that Apollo landings should each aim at the recovery of at least 150 pounds of lunar material. The report is also critical of the somewhat peripheral part which seems to be played by the scientific experiments associated with Apollo. First of all, the group would like to see a greater interval between successive flights so as to allow more time for the design of experiments. Those destined for the first few flights had to be assembled in such a hurry that only instruments whose development was substantially complete could be included. In general, the report asks for "changes in management structure that will ensure a greater part for science in the Apollo program".

Specifically, it complains that there is not enough financial support for the development of new instruments needed in the exploration of the Moon-"seed money", as the study group puts it. As a result, the report infers, fewer people are able to design lunar experiments than circumstances require. For one thing, the study group asks that NASA should spend more than the $\$ 1$ million to $\$ 2$ million a year so far devoted to "experiment definition". The committee also complains about the brief warning of impending spaceflights, and asks that scientists should have at least 90 days warning of the deadlines for submission of proposals. The study group openly says that "since the actual dollars required to ensure a body of competent experiments and experimenters is a very small percentage of the total dollars spent on operating the program, it seems to be false economy to restrict this essential 'seed money' and, in so doing, to jeopardize the objectives and the scientific returns of the space program".

The report also criticizes the process of selection of experiments as being unnecessarily complicated and time-consuming. And there is concern about the way the analysis of lunar samples is organized. The board is not convinced that the Lunar Receiving Laboratory at Houston is up to its task. Acknowledging that difficulties of this kind are common at the start of new 
enterprises, the study group nevertheless says that "if serious deficiencies persist, it is of the utmost importance that they be corrected in order not to degrade the scientific value of the samples. This matter requires immediate attention in order to avoid the possible necessity of delaying the examination of samples returned by future missions". This raises, in short, the horrific prospect of the Houston Laboratory as a kind of museum from the start.

\section{NUCLEAR EXPLOSIONS}

\section{No Panic on Amchifka}

The United States Atomic Energy Commission has issued a factual but reassuring report of the consequences of the megaton explosion of a nuclear weapon $4,000 \mathrm{ft}$ beneath the surface of Amchitka Island in Alaska on October 2. By now, of course, it is widely known that on this occasion, the explosion did not trigger off an earthquake of any size. The AEC says that the explosion itself registered 6.5 on the Richter scale, which is what had been predicted in advance. It does, however, seem that there were "a few rock slides and earth slumps" along the sea coast, together with some cracking of roadways and movement of road embankments saturated with water. In some places, temporary buildings were moved by the explosion but there was no damage to the airfield or to the utilities on the island.

The most serious damage seems to have been immediately above the point of the explosion, where some side panels in a workshop were shaken loose. The explosion was recognized easily by people even as far away as twenty-eight miles, in the north-west of the island, although "the ground motion was barely perceptible" on the mainland 200 miles away. It has already been reported that shock waves were felt strongly, about 11 seconds after the explosion, on the warship Princeton, about eight miles north-west of the island. The AEC says that such water waves as there may have been could not have exceeded two inches, and that the only earth movements consisted of a great many small tremors immediately around the cavity that came to an end after broken rock above the cavity collapsed into it a day and a half after the explosion. The surface of the island is however permanently scarred by a saucer shaped depression twenty feet deep and some hundreds of feet across. By all accounts, there has been no damage to the biological environment. Birds are said to have continued in occupation and trout and salmon have survived the over-pressure produced in lakes and streams although some sticklebacks were killed by concussion in nearby ponds. A variety of animals, including crabs and sea otters, are said to have been unaffected by the explosion although the AEC promises to keep the ecological effects under continuing review.

\section{DEFENCE RESEARCH}

\section{Half Settilement at MIT}

THE disturbances at the Massachusetts Institute of Technology earlier this week are a surprising sequel to what seems to have been a friendly encounter between the president, Dr Howard W. Johnson, and the faculty at the institute on October 22 , when the report of the review panel on special laboratories was discussed. By all accounts, only 15 out of 450 members of the faculty opposed the recommendation that the two principal laboratories, the Lincoln Laboratory and the Instrumentation Laboratory, which have been largely concerned with defence research, should gradually shift their emphasis towards the solution of "domestic and social problems". The position of the two laboratories was first given prominence by student protest in 1968 .

In his statement at the faculty meeting, Dr .Johnson said that the future of the two laboratories was critical for the institute. It has been aceepted that there should be a change in the direction of the laboratories -the question was how best to satisfy the legitimate interests of MIT and not the government. He said that it was also necessary to protect the interests and integrity of those working at the laboratories. The final report of the review panel, from which four of the twenty-two members dissented, recommends that the shift in direction should be accompanied by the declassification of a large part of the workers in the laboratories, the development of better relationships between the faculty and the students at the laboratories, and the creation of a standing committee to review the programme of the laboratories.

\section{GEOPHYSICS \\ New Laboratory}

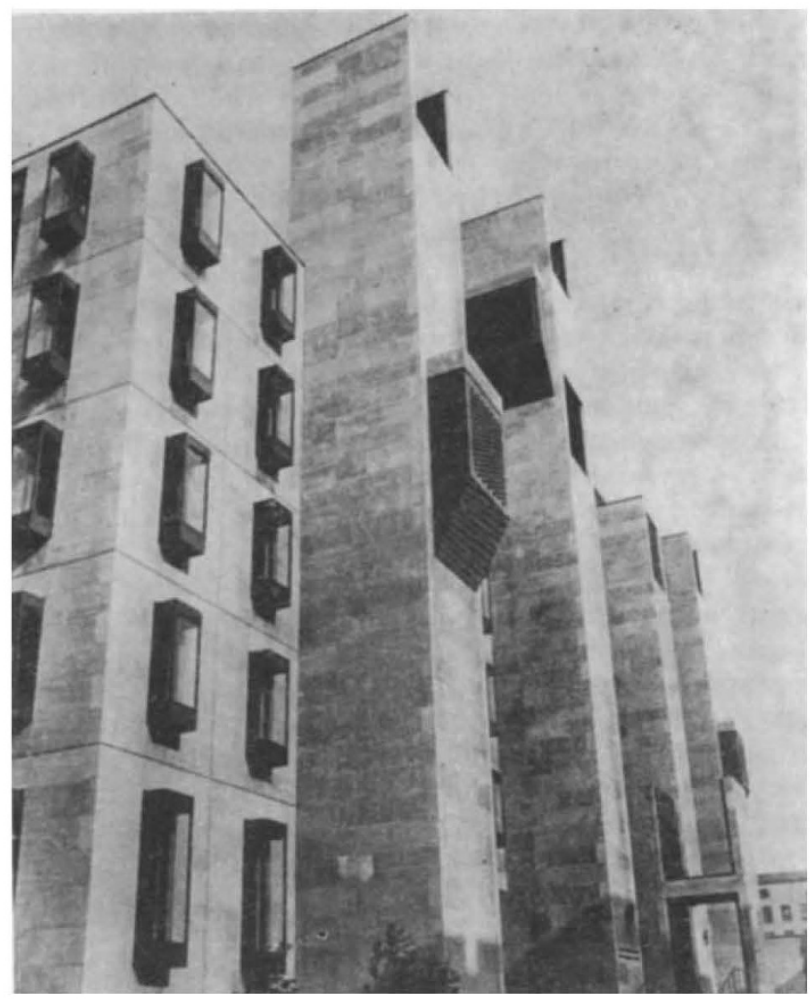

The Henry Hinds Laboratory for the Geophysical Sciences at the University of Chicago was officially opened on October 14. The building, which is dominated by ten tower appendages, has been designed by I. W. Colburn \& Associates Inc. of Chicago and is said to be in the "contemporary gothic" style. It cost $\$ 5$ million, partly supplied by the late Mr Henry Hinds, an oil geologist. 